\title{
O curso Aluno Integrado no município de Naviraí - MS: expectativas e conhecimentos adquiridos pelos alunos participantes
}

\author{
Luana A. Ayala ${ }^{1}$, Elizabeth M. Rocha ${ }^{2}$
}

${ }^{1}$ Programa de Pós-graduação em Educação- Universidade Federal da Grande Dourados (UFGD) - Dourados-MS- Brazil

2Programa de Pós-graduação em Educação- Universidade Federal da Grande Dourados (UFGD) - Dourados, MS- Brazil

luhanaayala@hotmail.com, Elizabeth.matosrocha@gmail.com

\begin{abstract}
This study proposes reflection on the Integrated Student course developed in the city of Ashland - MS, while Axis Integrated Proinfo. The aim of the study was to understand the interests of the students to participate in that course emphasizing about the desired expectations of teacher students in the face of experienced study. The methodology used was qualitative based on the case study. Through this study it was found that the Integrated Student course proved within the expectations of students, in giving the theoretical calculation related to Information Technology. From a practical point of view, it has not met expectations, since the topic was related to assembling a computer not. Another aspect that was evident in the study was the discontinuation of the proposal in the face of contingencies established by the Brazilian government, the Integrated Proinfo since 2015.
\end{abstract}

Resumo. Este estudo propõe reflexão sobre o curso Aluno Integrado desenvolvido no município de Naviraí - MS, enquanto eixo do Proinfo Integrado. O objetivo do estudo foi o de conhecer os interesses dos alunos em participar do referido curso enfatizando as expectativas almejadas dos cursistas em face do estudo vivenciado. A metodologia utilizada foi a de qualitativa com base no estudo de caso. Por meio desse estudo verificou-se que o curso Aluno Integrado se mostrou dentro das expectativas dos alunos, no que confere ao cômputo teórico relacionado à Informática. Do ponto de vista prático, não atendeu a expectativa, visto que o tópico que se relacionou à montagem de um computador não aconteceu. Outro aspecto que ficou evidenciado no estudo foi a descontinuidade da proposta em face do contingenciamento estabelecido pelo governo brasileiro, ao Proinfo Integrado, desde 2015.

\section{Introdução}

A sociedade contemporânea vem passando por grandes transformações políticas, econômicas e sociais que se desenvolvem em um processo acelerado caracterizando, assim, um momento histórico em que as relações se formam a partir da informação e DOI: $10.5753 /$ cbie.wie.2016.747 
V Congresso Brasileiro de Informática na Educação (CBIE 2016)

Anais do XXII Workshop de Informática na Escola (WIE 2016)

interação, criado a partir de uma cultura informática e virtual, derivada de uma série de fatores e criações tecnológicas e científicas que favorecem movimento intrigante que envolve a sociedade com as novas tecnologias desenvolvidas no ciberespaço, transformando a maneira de fazer comunicação de forma maleável e interativa. (LÉVY, 1999).

Diante desse contexto que atrai e causa entusiasmo nos jovens e adolescentes e receio por parte de muitos professores, a escola está sendo compelida a se adaptar aos formatos tecnológicos que ampliam e expandem a comunicação e interação humana. Assim, as políticas públicas no campo educacional visam suprir a necessidade de formar professores que saibam lidar e ensinar por meio das tecnologias digitais. Com base nisso, um dos desafios da educação está em preparar os alunos para lidar com a sociedade da informação. Nesse esteio, o governo federal, por meio do MEC, criou o Programa Nacional de Formação continuada em Tecnologia Educacional (ProInfo Integrado).

Esse programa, vinculado ao Ministério da Educação (MEC), foi criado em 2009 e teve abrangência nacional em parceria com os Núcleos de Tecnologia Educacional (NTE) dos estados brasileiros, em versões que aconteceram, consecutivamente, até o ano de 2015. O ProInfo Integrado disponibilizou, em seu formato, os seguintes cursos: Introdução à Educação Digital (60h); Tecnologias na Educação: ensinando e aprendendo com as TIC (60h); Elaboração de Projetos (40h); Redes de Aprendizagem (40h) e o Aluno Integrado (160H). Esse trabalho, portanto, trata, especificamente, de uma reflexão sobre o curso voltado ao estudante, chamado de Aluno Integrado, a partir de um relato de caso.

$\mathrm{Na}$ sua essência, a proposta do Aluno Integrado, voltado para estudantes das escolas públicas, do $1^{\circ}$ e $2^{\circ}$ ano do ensino médio, objetivou ampliar as possibilidades de ensino e aprendizagem nessas escolas, com o apoio das Tecnologias da Informação e Comunicação. A partir dessa formação, os alunos ficariam capacitados a acessar e viabilizar, juntamente com seus professores, o ambiente virtual de aprendizagem eproinfo. O cerne da proposta se pautou na promoção e inclusão digital (BRASIL, 2013).

De acordo com o projeto Aluno Integrado o curso teve duração de quatro meses, o público-alvo foram alunos do $1^{\circ}$ e $2^{\circ}$ ano do Ensino Médio. O curso foi pensado para acontecer no formato à distância, pela plataforma e-proinfo, com um encontro presencial de dezesseis horas.

O momento presencial estabeleceu condições para suprir os cursistas, em termos das informações imprescindíveis para o êxito, tendo em vista a capacitação do aluno para o uso da plataforma, que requereu dos alunos, no mínimo, 2 horas diárias disponíveis para estudo. 
Em termos da infraestrutura, foi necessário que a escola pública tivesse laboratório de informática com acesso à internet com velocidade mínima de 512bps, de modo a permitir ao aluno fazer o curso. A proposta teórica do curso foi pensada para utilizar a plataforma e-proinfo. O curso foi executado pela Secretaria de Educação Básica e contou com a participação das universidades, secretarias de educação, Núcleos de Tecnologias Educacionais (NTE), enquanto instituições interessadas em desenvolver a inclusão digital (BRASIL, 2013).

A proposta do projeto Aluno Integrado pretendeu aumentar o aprendizado dos alunos com base na produção e interpretação de textos, bem como aumentar o fluxo comunicacional promovendo o desenvolvimento humano por meio da TIC. O impacto dessa proposta foi o de capacitar cada vez mais alunos para auxiliar os professores, gestores e comunidade no desenvolvimento de projetos sob o viés da Informática aplicada à Educação de modo a cooperar na formação dos demais alunos e assim propiciar a multiplicação dos conhecimentos. (BRASIL, 2013).

Considerando a proposta do curso Aluno Integrado surgem algumas questões, como: quais aprendizados são efetivamente incorporados ao conjunto de saberes da escola? quais as expectativas dos alunos perante o curso? que metas foram cumpridas e quais valores agregados, visto que há real possibilidade de descontinuidade?

Deste modo, considerando o cenário do curso Aluno Integrado, fez um estudo de modo a identificar se as expectativas e interesses dos alunos, foram alcançadas, elencando os aspectos fortes e frágeis dessa proposta. O local da pesquisa foi uma escola pública estadual situada no município de Naviraí-MS. A proposta visou, ainda, conhecer os interesses e a opiniões dos alunos em participar do referido curso do ProInfo Integrado, identificando se as expectativas almejadas dos alunos perante o curso foram supridas com base no aprendizado e participação nas atividades propostas.

\section{Procedimentos Metodológicos}

Foi desenvolvida uma pesquisa qualitativa, de natureza descritiva. Trata-se de um relato de caso relacionado ao desenvolvimento do Curso Aluno Integrado. Dessa forma, “o pesquisador qualitativo pauta seus estudos na interpretação do mundo real, preocupando-se com o caráter hermenêutico na tarefa de pesquisar sobre a experiência vivida dos seres humanos" (OLIVEIRA, 2008, p.7). 
O curso Aluno Integrado foi desenvolvido no ano de 2014 em quatro escolas estaduais da cidade de Naviraí-MS. Para a construção desse estudo optou-se pela escolha de apenas uma das escolas, para que assim fosse possível acompanhar todo o processo do curso. A escola em questão trata-se de uma instituição localizada no centro da cidade com aproximadamente 900 alunos matriculados, distribuídos nos três períodos. Para a escolha dos 14 alunos que participaram do curso, a escola optou por sorteio devido ao grande número de interessados.

Após o sorteio, a Professora Gerenciadora dos Recursos Midiáticos (PROGETEC) e a tutora do curso fizeram uma reunião com os pais e os alunos explicando sobre o curso e a importância de não desistir, por esse motivo os pais assinaram um termo de responsabilidade se comprometendo a não deixar o filho desistir. Esse procedimento investigativo teve como sujeitos: o os quatorze alunos participantes do curso da escola pesquisada que serão identificados como A1 aluno 1 e assim sucessivamente.

Este estudo contou com várias fases para sua execução. A primeira foi composta por estudos sobre a temática proposta para que assim, fosse possível ter embasamento teórico, para melhor por em prática a pesquisa que aqui se desenvolveu. Essa fase foi de total importância, pois leva a caminhar paralelamente à observação e possibilitou ao observador ampliar seu conhecimento e a notar relações entre a prática e a teoria, além de sugerir focos para uma atenção mais sistemática. Também ocorreram visitas prévias ao Núcleo de Tecnologias Educacionais (NTE) e a escola escolhida para pedir a autorização para o desenvolvimento da pesquisa, que foi concedida (ANDRÉ, 1987)

$\mathrm{Na}$ segunda fase, ainda no início do curso, procedeu-se a elaboração de questionários com questões abertas e fechadas e a aplicação com os alunos, para assim conhecer as expectativas iniciais com curso e quais os interesses em participar do curso. Após três semanas de curso houve a preparação e desenvolvimento de um segundo questionário com questões abertas aos alunos ao fim do curso.

O principal intuito dos dois questionários foi o de investigar se as expectativas iniciais foram alcançadas e se o saber adquirido foi relevante para os discentes. A quarta etapa consistiu na categorização, dos questionários que foram analisados e comparados com as ideias e conceitos da área de Tecnologias educacionais.

\section{Análise e Discussão dos Dados}

A seguir serão apresentados os dados adquiridos através dos dois questionários aplicados aos alunos que foram divididos entre questionários de opiniões iniciais e finais, para, assim, contrapor as ideias dos alunos com relação ao curso e verificar as contribuições do mesmo para a aprendizagem dos participantes. 
V Congresso Brasileiro de Informática na Educação (CBIE 2016)

Anais do XXII Workshop de Informática na Escola (WIE 2016)

\subsection{Opiniões iniciais dos participantes do curso Aluno Integrado}

Os dados apresentados no quadro I apontam os principais interesses dos alunos em participar do curso Aluno Integrado

Quadro I: Interesse em participar do curso Aluno Integrado

\begin{tabular}{|l|l|c|}
\hline Interesses/Expecta tivas & \multicolumn{1}{|c|}{ Opiniões } & Total de falas \\
\hline Aspectos Profissionais & Conseguir um bom emprego Obter um & 03 \\
& certificado Melhorar o currículo & 03 \\
\hline Aspectos Educacionais & Adquirir mais conhecimentos na área & 01 \\
\hline Motivos Pessoais & & 02 \\
\hline Outros & Estar atualizada sobre informática. & 01 \\
\hline Total & Por ter participado de outros cursos sobre TIC & $\mathbf{1 4}$ \\
\hline
\end{tabular}

Fonte: autoria própria

Com base no quadro I é possível verificar que o principal interesse dos alunos em participar do curso Aluno Integrado esteve relacionado ao futuro profissional, demonstrando que os jovens estão preocupados com a empregabilidade e principalmente, com a concorrência que há no mercado de trabalho, já que em muitas situações eles destacaram que o certificado será um diferencial em seu currículo. Dentre as falas apenas duas destacaram a participação no curso por motivos de satisfação em aumentar os conhecimentos.

Pochmann (2005) explica que atualmente a filosofia das famílias de classe média está no ideário de ascensão social com a sua contínua busca tanto da elevação de sua participação relativa nos bens e serviços da sociedade como no maior nível de prestígio e status social. As famílias estão vendo na educação a oportunidade de um futuro melhor. Nesse sentido, considerando a atual conjuntura capitalista, ao que aponta que a escola tem cada vez mais preparado os alunos para os ideais competitivos.

Diante desse contexto, Arriada e Ramos (2013) relatam a inserção das tecnologias na escola passou a ser vista como preparação para mão de obra qualificada, e assim mais uma ideia passou a fazer parte desse cenário à competitividade. Segundo as autoras ao priorizar a significação dessas duas palavras, os princípios humanistas e emancipatórios acabam se desfazendo, assim a questão central a ser apresentada não é apenas "qual a função que a educação desempenha num dado momento, numa dađa1 
V Congresso Brasileiro de Informática na Educação (CBIE 2016)

Anais do XXII Workshop de Informática na Escola (WIE 2016)

sociedade, mas sim qual a função que a educação deve desempenhar, face à natureza humana" (ARRIADA e RAMOS, 2013).

No que se refere aos conhecimentos que desejam adquirir através do curso pode-se destacar algumas falas dos alunos

Além de ser uma oportunidade boa eu acredito que esses conhecimentos serão muito importantes para meu futuro profissional porque será algo a mais para $\operatorname{mim}(\mathrm{A} 2)$;

Poderá me ajudar a ingressar em um bom trabalho, eliminando concorrentes que não tem essa mesma formação que a minha (A4);

Podem me ajudar no dia-a-dia com necessidades que podem aparecer e um diploma me diferenciará das demais pessoas quando eu for procurar um emprego futuramente (A8).

Ao analisar as falas é possível averiguar que mais uma vez os alunos desejavam ter o conhecimento para enriquecer o currículo e futuramente concorrerem a um emprego. Porém, a fala desses alunos causa certa preocupação, por serem tão novos e já estarem com o ideário de competitividade que a sociedade capitalista impõe.

Mesmo tendo consciência de que o curso Aluno Integrado tem como um dos objetivos qualificar os alunos para o mundo do trabalho acredita-se que a escola já poderia apresentar para eles a importância de se prepararem não só para o trabalho, mais para atuarem na sociedade em si.

Sabe-se que "não se pode desconsiderar do trabalho educativo a necessidade de se formar para o mundo do trabalho, entretanto é necessário que os aspectos econômicos não se sobreponham ao social" (GENTILI; SILVA, 2012, p.10).

\subsection{Avaliação final dos alunos a respeito do desenvolvimento do curso Aluno Integrado}

A respeito das expectativas iniciais e se os saberes almejados foram supridos dos 14 alunos participantes 10 relataram que o curso proporcionou o conhecimento desejado e apenas 3 relataram que nem todas foram alcançadas. Como é possível ver nas seguintes falas:

Parte delas, pois tinha muita expectativa em aprender a configurar computadores, formatar, terei que fazer outros cursos para aprender sobre, mais sobre a parte física do computador gostei da aprendizagem (A4);

Nem todas, porque pensei que iria mexer com máquinas, aprender sobre instalações, mais de um modo geral foi bom também, aprendi coisas que não sabia sobre computador. (A10); 
V Congresso Brasileiro de Informática na Educação (CBIE 2016)

Anais do XXII Workshop de Informática na Escola (WIE 2016)

Sim, mas não totalmente, pois deveria ter me dedicado mais, me esforçado (A9).

Sim, pude enriquecer meus conhecimentos sobre PC, minhas expectativas foram supridas (A6);

Quanto à participação no curso Aluno integrado todos os 14 alunos a descreveram como satisfatória e pontuam que se dedicaram para aprender coisas novas e fizeram amigos, como é possível ver em algumas respostas:

Foi muito bom ter feito o curso, gostei muito, apesar das dificuldades, consegui concluir com sucesso e conheci pessoas muito legais (A7);

Nesse curso aprendi várias coisas, até mesmo sobre minha ortografia e meu senso critico ficou bem melhor, a PROGETEC sempre me ajudava (A1);

Descrevo que foi muito bom, aprendi várias coisas sobre computador que nem imaginava como a limpeza, por exemplo (A4);

Foi muito boa, fiz amigo e aprendi coisas novas, sem dúvidas valeu a pena (A12).

Nesse quesito observa se que poucos alunos ficaram insatisfeitos com o curso e o principal motivo destacado foi a falta de aulas práticas. Ao analisar os objetivos do curso observa-se que o foco não é oportunizar o conhecimento prático e sim debates sobre as TIC e consequentemente o conhecimento de algumas funções como foi possível verificar através do objetivo "desenvolvimento de habilidades relacionadas ao uso qualitativo da internet, processadores de texto, planilha de cálculos, banco de dados, software de apresentação, sistemas operacionais e manutenção de hardware" (BRASIL, 2013, p. 03).

Contudo, o curso Aluno Integrado poderia propiciar um conhecimento mais prático, mas para tanto seria necessárias reformulações, principalmente no que diz respeito à preparação dos tutores e PROGETEC. Sabe-se que o curso apresentava muitos vídeos de empresas, produção de computadores, o processo de montagem, os nomes das principais peças, contudo foi visível que os alunos esperavam mais.

\section{Considerações Finais}

O objetivo do estudo foi o de conhecer os interesses dos alunos em participar do referido curso enfatizando as expectativas almejadas dos cursistas em face do estudo vivenciado. Nesse sentido, o pesquisador apresenta algumas expectativas e de certa form 93 
V Congresso Brasileiro de Informática na Educação (CBIE 2016)

Anais do XXII Workshop de Informática na Escola (WIE 2016)

faz algumas antecipações do que espera do objeto de estudo e nessa pesquisa não foi diferente, esperou-se que os alunos iriam relatar que se interessaram pelo curso por gostarem de tecnologias e quererem aprimorar os conhecimentos.

Contudo, foi relatado que o principal interesse era o certificado e o currículo. A fala mais emblemática desse cenário foi "o curso poderá me ajudar a ingressar em um bom trabalho, eliminando concorrentes que não tem essa mesma formação que a minha" (A4). Essa constatação causou uma reviravolta na pesquisa, já que essa informação não era esperada, alunos de ensino médio com uma visão tão moldada no formato da competitividade.

Por um lado foi importante verificar que os jovens estão preocupados com o futuro profissional, todavia ao relataram que se interessaram pelo curso por causa do certificado gerou preocupação, pois o conhecimento deviria ser a principal motivação. A escola deve integrar em suas metas a preparação dos alunos não só para o mercado de trabalho, mas também para atuarem em sociedade, serem críticos, autônomos, conhecedores de seus direitos e deveres.

Como esse estudo propôs verificar ainda as contribuições em participar do curso Aluno Integrado, ao fim foi entregue outro questionário aos alunos e mais uma vez as respostas surpreenderam, pois os relatos demonstraram uma visão diferente da inicial. Os alunos pontuarão como contribuições a melhoria na escrita, o conhecimento adquirido sobre computadores e também o desenvolvimento do senso crítico. Em muitas falas foi destacado que o trabalho da PROGETEC foi imprescindível para a promoção desses conhecimentos.

Ponderando sobre o estudo foi possível constatar que o curso Aluno Integrado possibilita um aprendizado muito rico aos participantes. Primeiro, por propiciar o debate nas escolas sobre o uso das tecnologias digitais, estas que causam tanto fascínio nos jovens e que precisa cada vez mais fazer parte do cotidiano das instituições de ensino. Segundo, porque possibilita aos alunos aprimorar e enriquecer os conhecimentos sobre computadores, a evolução dessas máquinas, o processo de fabricação, como resolver alguns problemas simples envolvendo computadores.

Além desses conhecimentos na escola pesquisada foi possível verificar outras contribuições como, por exemplo, a melhoria significativa na percepção dos alunos sobre o que realmente é importante o conhecimento, ao fim do curso em vez de destacar como benéfico o certificado, apontarão o conhecimento adquirido como o primordial.

Os participantes apresentaram ainda melhorais significativas no que se referem à escrita, se tornando assim sujeitos do seu próprio conhecimento, já que viram a necessidade de empenho para conseguir acompanhar o desenvolvimento do curso. 
V Congresso Brasileiro de Informática na Educação (CBIE 2016)

Anais do XXII Workshop de Informática na Escola (WIE 2016)

O principal entrave se resumiu na falta de aulas práticas na medida em que é notável que sejam necessárias reformulações, investimento e principalmente numa preparação mais ampla para os responsáveis por ministrar o curso. Por ser o primeiro ano de oferta do curso Aluno Integrado no município de Naviraí-Ms foi louvável o bom aproveitamento que apresentou.

É notável a pertinência de novas pesquisas sobre o Curso Aluno Integrado, vinculando novas escolas como foco de pesquisas, até mesmo para contrapor e verificar se as contribuições serão as mesmas, bem como averiguar se nos próximos cursos houve melhorias e modificações. Enfim a experiência de desenvolver esta pesquisa possibilitou um aprendizado muito rico e acredita-se que o conhecimento adquirido foi significativo e profícuo. Outro aspecto que ficou evidenciado no estudo foi a descontinuidade da proposta em face do contingenciamento estabelecido pelo governo brasileiro, ao Proinfo Integrado, desde 2015.

\section{Referências}

ANDRÉ, M. E. D.A. A Pesquisa no cotidiano escolar. VIII Encontro de Pesquisadores da Região Sul, Porto Alegre, 1987.

ARRIADA, M. C.; RAMOS, E. M. F. Redes de Aprendizagem: guia do cursista. 1. Ed. Brasília, DF: Secretaria de Educação à distância, 2013.

BRASIL. Ministério da Educação. Secretaria de Educação Básica. Projeto Aluno Integrado. Brasília, 2013. Disponível em: http://portal.mec.gov.br/component/tags/tag/34610. Acesso em: 10 jul 2016.

GENTILI, P. A. A; SILVA, T.T. (Orgs). Neoliberalismo, Qualidade total e Educação: visões críticas. 14. Ed. Petropolis, RJ: Vozes, 2012.

LÉVY, P. Cibercultura. São Paulo: Ed. 34, 1999;

OLIVEIRA, C. L. Um apanhado teórico-conceitual sobre a pesquisa qualitativa: tipos, técnicas e características. Revista Eletrônica Travessias, Cascavel, vol. 2, n. 3, 2008. Disponível em <http://e-revista.unioeste.br/index.php/travessias/search/results>. Acesso em 10 nov. 2014.

POCHMANN, M. Desemprego e/ou precarização, o drama da classe média e seus filhos. Portal Popular, 2005 Artigo disponível em: www.portalpopular.org.br. Acesso em: 04 abr. 2014. 